\title{
openheart BISMICS consensus statement: implementing a safe minimally invasive mitral programme in the UK healthcare setting
}

\author{
Hunaid A Vohra, ${ }^{1}$ M Yousuf Salmasi (D) , ${ }^{2}$ Lueh Chien, ${ }^{3}$ Massimo Caputo, ${ }^{1}$ \\ Max Baghai, ${ }^{4}$ Ranjit Deshpande, ${ }^{5}$ Enoch Akowuah, ${ }^{6}$ Ishtiaq Ahmed, ${ }^{7}$ \\ Michael Tolan, ${ }^{8}$ Toufan Bahrami, ${ }^{9}$ Steven Hunter, ${ }^{10}$ Joseph Zacharias, ${ }^{11}$ on behalf \\ of the British and Irish Society for Minimally Invasive Cardiac Surgery
}

To cite: Vohra HA, Salmasi MY, Chien L, et al. BISMICS consensus statement: implementing a safe minimally invasive mitral programme in the UK healthcare setting. Open Heart 2020;7:e001259. doi:10.1136/ openhrt-2020-001259

HAV and MYS contributed equally.

Received 3 February 2020 Revised 26 February 2020 Accepted 25 August 2020

Check for updates

(C) Author(s) (or their employer(s)) 2020. Re-use permitted under CC BY-NC. No commercial re-use. See rights and permissions. Published by BMJ.

For numbered affiliations see end of article.

Correspondence to Dr M Yousuf Salmasi; $y$. salmasi@imperial.ac.uk

\section{ABSTRACT}

Disseminating the practice of minimally invasive mitral surgery (mini-MVS) can be challenging, despite its original case reports a few decades ago. The penetration of this technology into clinical practice has been limited to centres of excellence, and mitral surgery in most general cardiothoracic centres remains to be conducted via sternotomy access as a first line. The process for the uptake of mini-MVS requires clearer guidance and standardisation for the processes involved in its implementation. In this statement, a consensus agreement is outlined that describes the benefits of mini-MVS, including reduced postoperative bleeding, reduced wound infection, enhanced recovery and patient satisfaction. Technical considerations require specific attention and can be introduced through simulation and/ or use in conventional cases. Either endoballoon or aortic cross clamping is recommended, as well as femoral or central aortic cannulation, with the use of appropriate adjuncts and instruments. A coordinated team-based approach that encourages ownership of the programme by the team members is critical. A designated proctor is also recommended. The organisation of structured training and simulation, as well as planning the initial cases, is an important step to consider. The importance of pre-empting complications and dealing with adverse events is described, including re-exploration, conversion to sternotomy, unilateral pulmonary oedema and phrenic nerve injury. Accounting for both institutional and team considerations can effectively facilitate the introduction of a mini-MVS service. This involves simulation, team-based training, visits to specialist centres and involvement of a designated proctor to oversee the initial cases.

\section{INTRODUCTION}

In the current era of surgeon-specific outcome publication, cardiac surgery in the National Health Service has adopted a culture of evolutionary practice as opposed to revolutionary progression. ${ }^{1}$ The process of introducing new technologies and procedures is multifaceted, underpinned by the demonstration of both patient safety and clinical effectiveness. The innovation of techniques in minimally access mitral surgery (mini-MVS) has dominated the cardiothoracic community for the last two decades. Despite this, the penetration of this technology into clinical practice has been limited to centres of excellence, and mitral surgery in most general cardiothoracic centres remains to be conducted via sternotomy access as a first line. When compared with the conventional sternotomy approach, the procedure has implications for the surgeon, surgical team and postoperative healthcare staff with regard to surgical equipment, perioperative parameters and bedside adjuncts. ${ }^{2}$ These, in turn, requires a common agreement on the use of appropriate outcome metrics and benchmarking.

This consensus report will serve to comprehensively review the evidence for the practice of mini-MVS and use this to highlight the important considerations when initiating a new mini-MVS programme in a UK Healthcare Trust.

\section{EVIDENCE FOR MINI-MVS}

There are currently no adequately powered randomised controlled trial data comparing minimally invasive and conventional mitral valve surgery. However, mini-MVS has shown to have benefits demonstrated through specific metrics.

\section{Reduced postoperative bleeding}

One of the main worries of mini-MVS is the prospect for conversion to larger access owing to complications during surgery. However, mini-MVS has been found to reduce the need for re-exploration for bleeding 
compared with conventional sternotomy. Chitwood Jr and colleagues ${ }^{3}$ conducted a meta-analysis with 1553 participants showing reduced need for reoperation for bleeding with mini-MVS. Studies as early as 20 years ago also supported this notion, reporting 1.8 units fewer red blood cell transfusion in patients undergoing mini-MVS compared with conventional sternotomy. ${ }^{45}$

\section{Wound sepsis}

A smaller area of disruption in skin integrity allows for less inoculation with commensal microbes, especially in patients with diabetes, immunosuppression and higher body mass index. In an observational study conducted by Grossi et $a l^{5}$ the rates of septic wound complication in adult were $5.7 \%$ and $0.9 \%(\mathrm{p}=0.05)$ in median sternotomy and mini-MVS groups, respectively. This benefit also continued to be evident in elderly patients. ${ }^{6}$

\section{Patient satisfaction (shorten)}

Mini-MVS is associated with less postoperative pain and quicker return to normal activity. This translates to an improved quality of life in the early post- period. ${ }^{7}$ Glower et $a l^{8}$ showed that patients found that pain resolved more quickly and were able to return to activities of daily living up to 5 weeks earlier after mini-MVS compared with median sternotomy, perhaps a result of improved stabilisation of the thorax. ${ }^{3}{ }^{4}$ Furthermore, several studies have reported a demonstrable cost saving with mini-MVS, which could be a result of shorter length of stay (LOS) ${ }^{9-11}$

\section{Benefits in redo surgery}

Redo cardiac surgery is traditionally performed through a repeat median sternotomy. However, this procedure is technically challenging due to dense adhesions and has a considerable risk of injuries to cardiac and vascular structures, which are independent risk factors for mortality. ${ }^{12}$ In 2018, a meta-analysis with a total of 777 patients demonstrated mini-MVS as a valid alternative in redo MVS with significantly reduced rates in mortality, LOS and reoperation for bleeding. ${ }^{13}$

\section{TRAINING AND LEARNING CURVE}

Cautious management of the learning curve in surgical procedures can be a predictor of success. ${ }^{14}{ }^{15}$ Notably, the effect of learning curve on patient outcomes does not rely on individual surgeon's experience but the entire operative team. ${ }^{16}$

Monitoring the institution's progress through the learning curve is important. Cumulative sum (CUSUM) is a method to analyse a learning curve for a surgical team, variability within surgeons and to predict the number of cases required in order to overcome the learning curve. ${ }^{17}$ A study using CUSUM analysis in 3895 mini-MVS cases identified that adverse events (eg, conversion to sternotomy, re-exploration, stroke) reduced to the normal range of $10 \%$ after 250 cases. $^{18}$ In addition, greater than 50 cases per annum are required to maintain most the favourable results, amounting to an optimal procedure rate of one per week.

Yaffee $e$ e $a l^{19}$ demonstrated significantly shorter learning curves for totally endoscopic robotic mitral valve repair as a result of focused training in both technical and nontechnical skills. Comparatively, appropriate training in minimally invasive aortic valve replacement has also been possible without compromising patient safety, ${ }^{20}$ although the use of sutureless technology can aid with its learning curve $^{21}$ (an option not available for mini-MVS).

Devising a specific training programme or fellowship in a large volume centre will allow surgical proficiency to be reached in a timely fashion, thus facilitating the uptake of mini-MVS into the healthcare system more readily. Mentorship can be organised through the provision of dedicated fellowships and mentor schemes, which can be uniquely facilitated via specialist societies, such as British and Irish Society of Minimally Invasive Cardiac Surgery (BISMICS) and Society of Cardiothoracic Surgeons of Great Britain \& Ireland (SCTS). This can allow for targeted training of cardiac surgeons to promote the development of minimally invasive cardiac surgeons. Industry partners may play an important role in supporting proctors and surgeons.

\section{TECHNICAL CHALLENGES TO OVERCOME}

Mini-MVS is a technically demanding complex procedure. Considerations for new learning curves have been proposed in mini-MVS, namely altered incisions, reduced operative space, endoscopic instrumentation and aortic occlusion. ${ }^{22}$ The recommendations from this consensus statement are summarised in box 1 .

\section{Mitral valve repair}

Surgeons should be comfortable with the techniques of repair by operating on an adequate number of sternotomy access mitral procedures. The buildup to mini-MVS should also be graduated, ensuring that the 20 initial cases are straightforward, commonly P2 prolapse cases, which could be considered the simplest mitral procedure.

\section{Incision size}

The goal of a thoracotomy incision is to make it less than $5 \mathrm{~cm}$ in length, which has numerous patient benefits. For the initial cases, the skin incision can be made slightly longer to assist visualisation as it is the avoidance of sternotomy or no rib-spreading which provides clinical benefit. Beyond this, the relationship between volume and outcome remains true in mini-MVS, and it would not be unreasonable that the time to be considered an expert in mini-MVS may take a few years. Overcoming the challenges of operating in a reduced space is perhaps the largest challenge for the surgeon.

\section{Aortic occlusion}

Aortic occlusion is achieved currently by two techniques available to surgeons: (1) transthoracic clamp (TTC); 


\section{Box 1 Summary of recommendations for mini-MVS}

Patient selection

1. Patients with degenerative MR may be considered for minimally invasive mitral surgery with comparable outcomes to full sternotomy.

2. Patients who have had previous cardiac surgery and require intervention on the mitral valve can be considered for minimally invasive mitral surgery.

3. In the initial stages of implementing a mini-mitral service, low risk patients should be selected who also have a lower chance of complications (non-smokers, low BMI, non-diabetic, P2 prolapse).

\section{Cardiopulmonary bypass}

4. The use of either an endoaortic balloon or external cross clamp are recommended during minimal access mitral surgery, with little evidence of one preference over the other.

5. Femoral or direct aortic cannulation are both acceptable strategies to institute cardiopulmonary bypass.

6. The use of TOE guidance for arterial and venous cannula positioning during the institution of cardiopulmonary bypass is highly recommended.

\section{Staff/Governance}

7. The use of simulation with the surgical team prior to conducting the first live case of minimal access mitral surgery is highly recommended.

8. The implementation of a 'dry run' in the unit's theatre using the relevant equipment and staff is recommended.

9. Regular audit of initial mini mitral cases at a surgical unit, and subsequent mini mitral cases is highly recommended.

BMI, body mass index; TOE, transoesophageal echocardiography.

and (2) endoaortic balloon occlusion (EABO). The TTC technique is simpler and involves inserting a clamp through the intercostal spaces to clamp the ascending aorta. The EABO technique is associated with a longer learning curve as the procedure requires more monitoring and experience. It involves accessing the aorta through a catheter inserted either in the femoral artery or directly through the ascending aorta with an inflatable balloon at its tip. This is guided by transoesophageal echocardiography (TOE), the balloon is inflated and the aorta occluded. In a recent meta-analysis, the only advantage of TTC over EAOB was the reduction in aortic dissection complications (risk ratio $0.33,95 \%$ CI 0.12 to $0.93 ; \mathrm{p}=0.04){ }^{23}$

The use of aortic occlusion method currently remains entirely down to surgical preference and newer adjuncts for aortic occlusion are yet to penetrate surgical practice. Importantly, occluding the aorta through aortic cross-clamp time or EABO is a learning curve that the surgeons can only ascend during minimally invasive procedures. A useful option for TOE-guided cannulation would be gaining the patient's consent to practise percutaneous femoral cannulation on sternotomy or hemisternotomy cases could be a viable method for improving the surgeon's familiarity with this alternative strategy.

\begin{tabular}{ll} 
Table 1 & Levels of minimally invasive cardiac surgery \\
\hline Level 1 & Direct vision: (10-15 cm incisions) \\
Level 2 & Direct vision/video assisted with mini incisions $(4-6 \mathrm{~cm})$ \\
Level 3 & $\begin{array}{l}\text { Video directed and robot assisted with micro incisions } \\
(1.5-4 \mathrm{~cm})\end{array}$ \\
Level 4 & $\begin{array}{l}\text { Robotic (computer telemanipulation) and totally endoscopic } \\
\text { port incisions }(<1.5 \mathrm{~cm})\end{array}$
\end{tabular}

Adapted from Chitwood et al. ${ }^{9}$

\section{Endoscopic mini-MVS}

Thoracoscopes have been implemented in mini-mitral surgery for over two decades helping to reduce complications via improved visualisation, ${ }^{24}$ although familiarity for their use is required and mainly specialised centres advocate performing mini-MVS totally endoscopically. ${ }^{25}$ In 2008, Chitwood and colleagues described levels of mini-MVS based on the size of the incisions and progressive use of video-assisted or robotic-assisted surgery ${ }^{26}$ (table 1).

Robotic-assisted mini-MVS techniques, although safe and effective, are associated with more difficult learning curves. Robotic surgery provides ergonomic gains which improve the surgical process and the smaller incision sizes are favoured by patients. Current evidence is mostly based on observational studies, and therefore randomised trials may be required in order to definitively assess the advantages and disadvantages of these techniques. ${ }^{27}$

\section{IMPLEMENTING THE FIRST FEW CASES Early engagement with hospital and patients}

In most hospitals, all new procedures need prior approval from a hospital committee, which has ethical, cost, patient outcome and management considerations. This ensures patient safety, highlights clinical governance and maintains quality control. The hospital committee may have a specific application process and ask for prerequisite information prior to issuing favourable support. Usually, this involves description and indications of the proposed procedure, intended benefits, possible complications, summary of evidence base, estimated number of annual procedures to be performed and names of supporting colleagues. $^{28}$

Evidence suggests that patients prefer detailed explanations of their treatment and decisions made surrounding it. ${ }^{29}{ }^{30}$ Written material explaining why the department is employing the new procedure, evidence surrounding its use, as well as what patients should expect following the procedure should be offered containing visual aids and diagrams. Risks of mini-MVS should be explained openly and helps avoid confusion or anxiety.

\section{Selecting the initial cases}

In the initial period (first 20 cases), appropriate patient selection is key. This ensures patient safety and allows the surgeon and team to 'break in' to the novel procedure 
Table 2 Contraindications for minimal access mitral surgery

\begin{tabular}{|c|c|c|}
\hline Contraindication & $\begin{array}{l}\text { Implications for mini mitral } \\
\text { surgery }\end{array}$ & Methods to circumvent \\
\hline Prior right chest surgery or radiation & $\begin{array}{l}\text { Patients are at increased risk due to } \\
\text { pleural adhesions }\end{array}$ & $\begin{array}{l}\text { Preoperative CT scan can allow for operative planning with } \\
\text { specific adjuncts and techniques to avoid damage to major } \\
\text { structure }^{50}\end{array}$ \\
\hline $\begin{array}{l}\text { Severe peripheral atherosclerosis or chronic } \\
\text { peripheral arterial occlusive disease. Descending } \\
\text { aorta aneurysm, aortic dissection, aortic thrombus. }\end{array}$ & $\begin{array}{l}\text { Peripheral cannulation for CPB can be } \\
\text { particularly challenging for these patients }\end{array}$ & $\begin{array}{l}\text { Alternate routes of cardiopulmonary bypass to be considered } \\
\text { or full sternotomy }\end{array}$ \\
\hline $\begin{array}{l}\text { Prominent ascending aorta calcifications or } \\
\text { ascending aorta aneurysm/dilation }(>4.5 \mathrm{~cm})\end{array}$ & $\begin{array}{l}\text { Aortic clamping and antegrade } \\
\text { cardioplegia administration are challenging } \\
\text { in these patients }\end{array}$ & Consider endo-balloon or percutaneous mitral valve repair \\
\hline Moderate to severe aortic regurgitation (AR) & Difficulties with cardioplegia administration & Conventional sternotomy \\
\hline $\begin{array}{l}\text { Significant chest wall deformity (particularly severe } \\
\text { pectus excavatum) }\end{array}$ & $\begin{array}{l}\text { Challenging access to all intrathoracic } \\
\text { structures }\end{array}$ & Conventional sternotomy \\
\hline Severe mitral annular calcification & $\begin{array}{l}\text { Extensive decalcification of the mitral } \\
\text { annulus and reconstruction with a } \\
\text { pericardial patch is very challenging } \\
\text { through a minimal invasive approach }\end{array}$ & $\begin{array}{l}\text { Conventional sternotomy or percutaneous mitral valve } \\
\text { replacement }\end{array}$ \\
\hline
\end{tabular}

with as minimal complications as possible. In the early stages, should avoid

1. Very elderly.

2. Grossly obese.

3. current smokers.

4. High risk (high Euroscore).

5. Complex repairs (stick to straightforward annuloplasty $\pm \mathrm{P} 2$ resection).

In actual fact, it is these very patients who may benefit from mini-MVS the most. ${ }^{31} 32$ However, in the initial stages of implementation, the complication rate may be higher.

Other contraindications to mini-MVS that would persist beyond the initial cases should also be described and made clear in the institution's protocol. Although not absolute contraindications, each patient should be considered on an individual basis via a risk-benefit analysis and through the consideration of the multidisciplinary process. The contraindications to be considered have been outlined in table 2 .

\section{Equipment needs}

An important recommendation for familiarisation with mini-MVS technology is to make use of them during established open procedures. This includes the thoracoscope, knot pusher and TOE-guided cannulation (table 3). Space will be less restricted and safety for their use in these scenarios would not be compromised. Local departmental teaching attended by all involved personnel and team members from different specialties should also be delivered. This allows for the following opportunities:

1. Invited speakers from specialised centres or equipment companies.

2. Watching operative videos of the procedure

3. Exploring the rationale of the new technology.

4. Group discussion.

5. Handling of specialised instruments and discussion surrounding their use.

6. Agree to one case per day for the whole team to allow adequate time for a full debrief where each member of the team has a voice.

\section{Trainees and surgical assistants}

Establishing the new service should have a long-term vision that includes transferring the knowledge and skills to junior colleagues who can lead and participate in the service in subsequent years. Including trainees in visits to specialised centres, teaching sessions and group discussions surrounding the new procedure should be

Table 3 Technical aspects of minimal access mitral surgery and relevant ways to introduce into a new unit

\begin{tabular}{llllll}
\hline & $\begin{array}{l}\text { Attempts on } \\
\text { sternotomy mitral } \\
\text { cases }\end{array}$ & Wetlab & $\begin{array}{l}\text { Team-based } \\
\text { simulation }\end{array}$ & $\begin{array}{l}\text { Visit to specialist } \\
\text { centre }\end{array}$ & $\begin{array}{l}\text { Visit from } \\
\text { proctor to unit }\end{array}$ \\
\hline Mini thoracotomy & & $\sqrt{ }$ & & $\sqrt{ }$ & $\sqrt{ }$ \\
TOE-guided aortic cannulation & $\sqrt{ }$ & & $\sqrt{ }$ & $\sqrt{ }$ & $\sqrt{ }$ \\
Aortic occlusion & & & & $\sqrt{ }$ & $\sqrt{ }$ \\
Knot pushing & $\sqrt{ }$ & $\sqrt{ }$ & $\sqrt{ }$ & $\sqrt{ }$ & $\sqrt{ }$ \\
\hline Thoracoscopic adjunct & $\sqrt{ }$ & & &
\end{tabular}

TOE, transoesophageal echocardiography. 
encouraged. Assisting in the initial cases is also recommended.

The use of high-fidelity virtual reality simulation training has demonstrated benefit in many fields of minimally invasive surgery ${ }^{33-35}$ including thoracoscopic surgery. This helps shorten the learning curve outside the operating theatre and hence improve patient safety while new procedures are being implemented.

\section{Staff considerations}

The importance of team concordance and communication surrounding these new process entities are paramount. In this light, the need for simulation is highly recommended. Scheduling a visit to a customised simulation centre with specialised assessment equipment and simulated theatres is extremely useful. Specialised audiovisual equipment can allow for unique playback and feedback opportunities to allow team members to improve on personal aspects of communication. Promoting positive relations and trust between the team members play an important role in ensuring the efficient running of complex procedures. Studies in many surgical specialties have shown that the familiarity of team members is key to minimise operative-related complications, reduce operative time and improve patient outcomes. ${ }^{36} 37$

Devising one to two mini mitral-specific checklists is also highly recommended. This will help reduce untoward error related to equipment, staff or theatre processes. This may be used to benefit specific staff, or groups of staff, members, for example, scrub nurses when checking equipment preparation and theatre operating department practitioners when checking theatre and patient readiness.

It is important to note that initiating a novel mini-MVS service has significant benefits for the institution. For the staff, this can be a catalyst for improving team morale, selfbelief and skill progression. Becoming a unit that collectively leads in the implementation of new technology and techniques will carry both staff and patient benefit.

\section{DEALING WITH ADVERSE EVENTS}

Establishing a culture of objectivity is critical for the audit process. This involves the leading members of the service and team in promoting an ethos of openness, honesty and devoid of blame. Moving to a mini-MVS approach does expose the surgeon and his team to a different set of complications related to alternative cannulation strategies and new incisions. All adverse outcomes need to be clearly documented and each can be virtually eliminated by constant improvements in both technique and technology used. Regular conversations with a mentoring surgeon or team helps understand specific complications and leads to a lower incidence.

\section{Bleeding and re-exploration}

One of the underlying causes of conversion from mini-MVS to median sternotomy is bleeding, ${ }^{38}$ although literature has shown that mini-MVS leads to a reduction in bleeding and re-exploration compared with sternotomy. ${ }^{39}$ Management of postoperative bleeding should adhere to strict standards as with other cardiac surgical procedures. The need for adequate surgical re-exploration for severe haemorrhage should not be overshadowed by the desire to maintain the integrity of minimal access. ${ }^{39}$ In the first instance, hypothermia and acidosis should be closely monitored, and crystalloid administration should be minimised to avoid haemodilution. ${ }^{40}$ Additionally, excessive hypertension should be avoided, and mean arterial pressure levels should not be allowed to run higher than $90 \mathrm{~mm} \mathrm{Hg}^{41}$ and timely transfusion with blood products is required. ${ }^{42}$

Dense pulmonary adhesions are another cause of conversion to sternotomy. This is associated with patients with a background of pulmonary diseases. ${ }^{43}$ Hence, a detailed preoperative CT scan with anatomical consideration and detailed multi-disciplinary team discussion should be carried out in these patients.

\section{Pulmonary oedema}

There have been reports of unilateral pulmonary oedema (a rare but life-threatening complication) occurring after mini-MVS ${ }^{44}$ with the pathophysiology thought to be inflammatory related. The cause-effect relationship is yet to be established, as many cases of severe pulmonary oedema can also be observed following sternotomy access for cardiac procedures. Two landmark trials found a role for perioperative intravenous steroids in sternotomy cardiac patients for the significant reduction in the incidence of pulmonary oedema, ${ }^{45}$ although this has not been formerly trialled in mini-MVS. Retrospective studies in mini-MVS have found that the introduction of perioperative steroids in mini-MVS may lead to a reduced incidence of clinical and radiological pulmonary oedema. ${ }^{47}$ Careful ventilatory strategies may also need to be employed to reduced volume and barotraumarelated lung injury. ${ }^{48}$

\section{Phrenic nerve palsy}

The risk of phrenic nerve palsy with mini-MVS has been reported to increase by $3 \%$ compared with conventional sternotomy. ${ }^{39}$ This can have adverse implications as patients may experience respiratory distress and prolonged ventilation. ${ }^{49}$ It is speculated that phrenic nerve palsy results from excessive pull on pericardial traction sutures which are used for better visualisation of the left atrium. ${ }^{49}$ Therefore, measures to incise the pericardium further away from the phrenic nerve (preferably $>3 \mathrm{~cm}$ ) and avoid retraction sutures near the nerve to prevent extensive pull ${ }^{3}$ are advocated. It is important to note that phrenic injury is an avoidable complication, which gives emphasis to the importance of rigorous attention to this part of the procedure when training surgeons in mini-MVS.

\section{Pain}

Although mini-MVS confers a smaller incision, chronic pain can develop as a result of intercostal nerve damage. ${ }^{38}$ Randomised controlled studies are lacking in this area, 
although the use of various analgesic techniques has been reported. The use of a catheter inserted in close proximity to intercostal space before skin closure with administration of $75 \mathrm{mg}$ of $0.75 \%$ ropivacaine has been shown to eliminate early postoperative pain. ${ }^{38}$ Alternatively, intercostal nerve blockade combined with general anaesthesia has also been reported,$^{50}$ which was achieved by the administration of $0.5 \%$ ropivacaine from $\mathrm{T} 3$ to T7 prior to anaesthesia induction. Intractable cases of chronic pain secondary to intercostal nerve traction is likely to require input from neuropathic pain specialists to employ patient-specific therapy. Most cases of pain tend to resolve within 12 months, and many lessons can be drawn from thoracic surgical practice whose patients frequently have pain related to the intercostal nerve.

\section{CONCLUSION}

This consensus statement has outlined the important considerations and processes for establishing a workable, effective and sustainable mini-MVS service in a modern UK healthcare system. The aim of the authors is to promote standardised practice to allow the effective and safe dissemination of novel technology in healthcare for the betterment of patients requiring mitral surgery.

\section{Author affiliations \\ ${ }^{1}$ Cardiac Surgery, Bristol Heart Institute, Bristol, UK \\ ${ }^{2}$ Surgery and Cancer, Imperial College London, London, UK \\ ${ }^{3}$ Faculty of Medicine, Imperial College London, London, UK \\ ${ }^{4}$ Cardiothoracic Surgery, King's College Hospital NHS Foundation Trust, London, UK \\ ${ }^{5}$ Cardiology, King's College Hospital, London, UK \\ ${ }^{6}$ Cardiothoracic Surgery, South Tees Hospitals NHS Foundation Trust, \\ Middlesbrough, UK \\ ${ }^{7}$ Cardiac Surgery, Brighton and Sussex NHS LKS Royal Sussex County Hospital, Brighton, UK \\ ${ }^{8}$ Cardiac Surgery, St James Hospital, Dublin, Ireland \\ ${ }^{9}$ Cardiac Surgery, Harefield Hospital, Royal Brompton \& Harefield NHS Foundation Trust, London, UK \\ ${ }^{10}$ Cardaic Surgery, Sheffield Teaching Hospitals NHS Foundation Trust, Sheffield, UK ${ }^{11}$ Lancashire Cardiac Centre, Blackpool Victoria Hospital, Blackpool, UK}

Collaborators All authors collaborated to produce this article as members of the British and Irish Society for Minimally Invasive Cardiac Surgery (BISMICS).

Contributors All authors contributed to the production of this manuscript.

Funding The British Heart Foundation, Cardiovascular theme of NIHR Bristol Biomedical Research Centre, supported this work. The funders played no role in the design of the study, in the collection, analysis and interpretation of data, or in the decision to submit the manuscript for publication.

Competing interests $\mathrm{JZ}$ is a paid proctor for Edwards Lifesciences, Cryolife and Abbott.

Patient consent for publication Not required.

Provenance and peer review Not commissioned; externally peer reviewed.

Data availability statement No data are available.

Open access This is an open access article distributed in accordance with the Creative Commons Attribution Non Commercial (CC BY-NC 4.0) license, which permits others to distribute, remix, adapt, build upon this work non-commercially, and license their derivative works on different terms, provided the original work is properly cited, appropriate credit is given, any changes made indicated, and the use is non-commercial. See: http://creativecommons.org/licenses/by-nc/4.0/.

Correction notice This article has been corrected since it was first published. 'Massimo Caputo' has been added as the 4th author and a funding statement has now been included.
ORCID iD

M Yousuf Salmasi http://orcid.org/0000-0002-4085-1294

\section{REFERENCES}

1 Jarral OA, Baig K, Pettengell C, et al. National survey of UK consultant surgeons' opinions on surgeon-specific mortality data in cardiothoracic surgery. Circ Cardiovasc Qual Outcomes 2016;9:414-23.

2 Vohra H, Solinas M. Minimally invasive mitral valve surgery. New York: Nova Science Publishers, Inc, 2017.

3 Modi P, Hassan A, Chitwood WR. Minimally invasive mitral valve surgery: a systematic review and meta-analysis. Eur J Cardiothorac Surg 2008;34:943-52.

4 Cohn LH, Adams DH, Couper GS, et al. Minimally invasive cardiac valve surgery improves patient satisfaction while reducing costs of cardiac valve replacement and repair. Ann Surg 1997;226:421-8.

5 Grossi EA, Galloway AC, Ribakove GH, et al. Impact of minimally invasive valvular heart surgery: a case-control study. Ann Thorac Surg 2001;71:807-10.

6 Grossi EA, Galloway AC, Ribakove GH, et al. Minimally invasive port access surgery reduces operative morbidity for valve replacement in the elderly. Heart Surg Forum 1999;2:212-5.

7 Yamada T, Ochiai R, Takeda J, et al. Comparison of early postoperative quality of life in minimally invasive versus conventional valve surgery. J Anesth 2003;17:171-6.

8 Glower DD, Landolfo KP, Clements F, et al. Mitral valve operation via port access versus median sternotomy. Eur J Cardiothorac Surg 1998;14:143-7.

9 Chitwood J, Wixon CL, Elbeery JR, et al. Lust RMV minimally invasive mitral valve surgery, et al. video-assisted minimally invasive mitral valve surgery. J Thorac Cardiovasc Surg 1997;114:773-82.

10 Iribarne A, Easterwood R, Russo MJ, et al. Comparative effectiveness of minimally invasive versus traditional sternotomy mitral valve surgery in elderly patients. $J$ Thorac Cardiovasc Surg 2012;143:S86-90.

11 Cosgrove DM, Sabik JF, Navia JL. Minimally invasive valve operations. Ann Thorac Surg 1998;65:1535-9.

12 Park CB, Suri RM, Burkhart HM, et al. Identifying patients at particular risk of injury during repeat sternotomy: analysis of 2555 cardiac reoperations. J Thorac Cardiovasc Surg 2010;140:1028-35.

13 Daemen JHT, Heuts S, Olsthoorn JR, et al. Right minithoracotomy versus median sternotomy for reoperative mitral valve surgery: a systematic review and meta-analysis of observational studies. Eur $J$ Cardiothorac Surg 2018;54:817-25.

14 Bonaros N, Schachner T, Lehr E, et al. Five hundred cases of robotic totally endoscopic coronary artery bypass grafting: predictors of success and safety. Ann Thorac Surg 2013;95:803-12.

15 Burt BM, EIBardissi AW, Huckman RS, et al. Influence of experience and the surgical learning curve on long-term patient outcomes in cardiac surgery. J Thorac Cardiovasc Surg 2015;150:1061-8.

16 Elbardissi AW, Duclos A, Rawn JD, et al. Cumulative team experience matters more than individual surgeon experience in cardiac surgery. J Thorac Cardiovasc Surg 2013;145:328-33.

17 Vohra HA, Ahmed EM, Meyer A, et al. Knowledge transfer and quality control in minimally invasive aortic valve replacement. Eur J Cardiothorac Surg 2018;53:ii9-13.

18 Holzhey DM, Seeburger J, Misfeld M, et al. Learning minimally invasive mitral valve surgery: a cumulative sum sequential probability analysis of 3895 operations from a single high-volume center. Circulation 2013;128:483-91.

19 Yaffee DW, Loulmet DF, Kelly LA, et al. Can the learning curve of totally endoscopic robotic mitral valve repair be short-circuited? Innovations 2014;9:43-8.

20 Soppa G, Yates M, Viviano A, et al. Trainees can learn minimally invasive aortic valve replacement without compromising safety. Interact Cardiovasc Thorac Surg 2015;20:458-62.

21 Murzi M, Cerillo AG, Gilmanov D, et al. Exploring the learning curve for minimally invasive sutureless aortic valve replacement. $J$ Thorac Cardiovasc Surg 2016;152:1537-46.

22 Hunter S. How to start a minimal access mitral valve program. , 2013: 2, 774-8.

23 Rival PM, Moore THM, McAleenan A, et al. Transthoracic clamp versus endoaortic balloon occlusion in minimally invasive mitral valve surgery: a systematic review and meta-analysis. Eur J Cardiothorac Surg 2019;56:643-53.

24 Chitwood WR, Wixon CL, Elbeery JR, et al. Video-assisted minimally invasive mitral valve surgery. $J$ Thorac Cardiovasc Surg 1997;114:773-82. 
25 Casselman FP, Van Slycke S, Wellens F, et al. Mitral valve surgery can now routinely be performed endoscopically. Circulation 2003;108:48II--54.

26 Chitwood WR, Rodriguez E, Chu MWA, et al. Robotic mitral valve repairs in 300 patients: a single-center experience. J Thorac Cardiovasc Surg 2008;136:436-41.

27 Marin Cuartas M, Javadikasgari H, Pfannmueller B, et al. Mitra valve repair: robotic and other minimally invasive approaches. Prog Cardiovasc Dis 2017;60:394-404.

28 Vohra HA, Vaja R, lakovakis I, et al. Starting out in minimally invasive aortic valve replacement in the UK. Interact Cardiovasc Thorac Surg 2016;22:1-4

29 Howlader MH, Dhanji A-R, Uppal R, et al. Patients' views of the consent process for adult cardiac surgery: questionnaire survey. Scand Cardiovasc J 2004;38:363-8.

30 Hallock JL, Rios R, Handa VL. Patient satisfaction and informed consent for surgery. Am J Obstet Gynecol 2017;217:181.e1-181.e7.

31 Moscarelli M, Fattouch $\mathrm{K}$, Casula $\mathrm{R}$, et al. What is the role of minimally invasive mitral valve surgery in high-risk patients? A metaanalysis of observational studies. Ann Thorac Surg 2016;101:981-9.

32 Santana O, Reyna J, Grana R, et al. Outcomes of minimally invasive valve surgery versus standard sternotomy in obese patients undergoing isolated valve surgery. Ann Thorac Surg 2011;91:406-10.

33 Gallagher AG, Ritter EM, Champion H, et al. Virtual reality simulation for the operating room: proficiency-based training as a paradigm shift in surgical skills training. Ann Surg 2005;241:364-72.

34 Gurusamy KS, Aggarwal R, Loizidou M, et al. Virtual reality training for surgical trainees in laparoscopic surgery. Cochrane Database Syst Rev 2013;1:CD006575.

35 Jensen K, Ringsted C, Hansen HJ, et al. Simulation-based training for thoracoscopic lobectomy: a randomized controlled trial: virtualreality versus black-box simulation. Surg Endosc 2014;28:1821-9.

36 Xu R, Carty MJ, Orgill DP, et al. The teaming curve: a longitudinal study of the influence of surgical team familiarity on operative time. Ann Surg 2013;258:953-7.

37 Maruthappu M, Duclos A, Zhou CD, et al. The impact of team familiarity and surgical experience on operative efficiency: a retrospective analysis. J $R$ Soc Med 2016;109:147-53.

38 Fernandes A, Gaio Lima C, Paulo N, et al. Analgesia Management for Mitral Valve Repair Via Minithoracotomy - A Case Report. Rev Port Cir Cardiotorac Vasc 2017;24:197.

39 Cheng DCH, Martin J, Lal A, et al. Minimally invasive versus conventional open mitral valve surgery: a meta-analysis and systematic review. Innovations 2011;6:84-103.
40 Kutcher ME, Kornblith LZ, Narayan R, et al. A paradigm shift in trauma resuscitation: evaluation of evolving massive transfusion practices. JAMA Surg 2013;148:834-40.

41 Morrison CA, Carrick MM, Norman MA, et al. Hypotensive resuscitation strategy reduces transfusion requirements and severe postoperative coagulopathy in trauma patients with hemorrhagic shock: preliminary results of a randomized controlled trial. J Trauma 2011;70:652-63.

42 Society of Thoracic Surgeons Blood Conservation Guideline Task Force, Ferraris VA, Ferraris SP, et al. Perioperative blood transfusion and blood conservation in cardiac surgery: the Society of thoracic surgeons and the Society of cardiovascular Anesthesiologists clinical practice guideline. Ann Thorac Surg 2007;83:S27-86.

43 Vollroth M, Seeburger J, Garbade J, et al. Minimally invasive mitral valve surgery is a very safe procedure with very low rates of conversion to full sternotomy. Eur J Cardiothorac Surg 2012;42:e13-16.

44 Renner J, Lorenzen U, Borzikowsky C, et al. Unilateral pulmonary oedema after minimally invasive mitral valve surgery: a single-centre experience. Eur J Cardiothorac Surg 2018;53:764-70.

45 Dieleman JM, Nierich AP, Rosseel PM, et al. Intraoperative high-dose dexamethasone for cardiac surgery: a randomized controlled trial. JAMA 2012;308:1761-7.

46 Whitlock RP, Devereaux PJ, Teoh KH, et al. Methylprednisolone in patients undergoing cardiopulmonary bypass (SIRS): a randomised, double-blind, placebo-controlled trial. Lancet 2015;386:1243-53.

47 Keyl C, Staier K, Pingpoh C, et al. Unilateral pulmonary oedema after minimally invasive cardiac surgery via right anterolateral minithoracotomy. Eur J Cardiothorac Surg 2015;47:1097-102.

48 Zupancich E, Paparella D, Turani F, et al. Mechanical ventilation affects inflammatory mediators in patients undergoing cardiopulmonary bypass for cardiac surgery: a randomized clinical trial. J Thorac Cardiovasc Surg 2005;130:378-83.

49 Falk V, Cheng DCH, Martin J, et al. Minimally invasive versus open mitral valve surgery: a consensus statement of the International Society of minimally invasive coronary surgery (ISMICS) 2010 Innovations 2011;6:66-76.

50 Zhan Y, Chen G, Huang J, et al. Effect of intercostal nerve block combined with general anesthesia on the stress response in patients undergoing minimally invasive mitral valve surgery. Exp Ther Med 2017;14:3259-64. 


\section{Correction: BISMICS consensus statement: implementing a safe minimally invasive mitral programme in the UK healthcare setting}

Vohra HA, Salmasi MY, Chien L, et al. BISMICS consensus statement: implementing a safe minimally invasive mitral programme in the UK healthcare setting. Open Heart 2020;7:e001259. doi: 10.1136/openhrt-2020-001259corr1.

Co-author Massimo Caputo was previously omitted from the author list and has now been added as the 4th author. Additionally, the following funding statement has been added since the article was first published: "The British Heart Foundation, Cardiovascular theme of NIHR Bristol Biomedical Research Centre, supported this work. The funders played no role in the design of the study, in the collection, analysis and interpretation of data, or in the decision to submit the manuscript for publication."

Open access This is an open access article distributed in accordance with the Creative Commons Attribution Non Commercial (CC BY-NC 4.0) license, which permits others to distribute, remix, adapt, build upon this work non-commercially, and license their derivative works on different terms, provided the original work is properly cited, appropriate credit is given, any changes made indicated, and the use is non-commercial. See: http://creativecommons.org/licenses/by-nc/4.0/.

(C) Author(s) (or their employer(s)) 2020. Re-use permitted under CC BY-NC. No commercial re-use. See rights and permissions. Published by BMJ.

Open Heart 2020;7:e001259corr1. doi:10.1136/openhrt-2020-001259corr1

Check for updates 